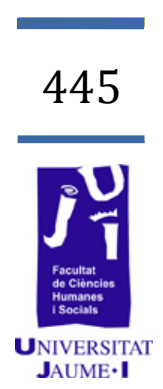

\title{
La comprensió de les intencions comunicatives en adults amb síndrome de Down i altres tipus de discapacitat intel'lectual
}

Eloy Soria-Izquierdo esoria@uji.es

Clara Andrés-Roqueta candres@psi.uji.es 
Antecedents: entre les habilitats de teoria de la ment (TM), la comprensió de les intencions comunicatives resulta essencial per a desenvolupar relacions socials i comprendre les accions d'altres persones. Entre altres poblacions, les persones amb síndrome de Down (SD) i altres discapacitats intel-lectuals (DI) presenten dificultats en aquest camp. Tanmateix, la competència sembla variable dins dels trastorns.

Objectius: aquest estudi pretén oferir una comparació de les intencions comunicatives en persones adultes amb SD i altres DI, ampliant la informació prèvia sobre aquest tema, així com observar la relació d'aquestes amb l'adquisició del llenguatge.

Mètodes i procediments: trenta-sis adults (divuit d'ells amb SD i divuit amb altres DI) es van avaluar amb una tasca de comprensió d'intencions comunicatives (les "Històries Estranyes», de Happé, 1994; tasca que és resolta entre els 4 i 10 anys d'edat en xiquets amb desenvolupament típic), juntament amb dues tasques receptives de llenguatge (gramàtica i vocabulari).

Resultats: tota la població amb DI (SD i DI amb altres dificultats) van demostrar un nivell baix en totes les tasques de les «Històries Estranyes». El grup amb DI obtingué, en general, més bons resultats que el grup amb SD. A més, el nivell de llenguatge va resultar clau en la resolució de la tasca.

Conclusions: les persones adultes amb SD presenten dificultats en la comprensió de les intencions comunicatives, encara que siguen més hàbils que altres adults en altres trastorns (ex. autisme) a l'hora de relacionar-se amb els iguals. Aquestes dificultats es relacionen, sobretot, amb el seu nivell de llenguatge.

Implicació: aquests resultats destaquen la importància de dur a terme una intervenció en la comprensió de les intencions comunicatives per a persones adultes amb SD en particular i DI en general, i així poder millorar la qualitat i percepció de les relacions socials amb els iguals.

Paraules clau: síndrome de Down (SD), intencions comunicatives, discapacitat intel-lectual (DI), llenguatge, teoria de la ment (TM), adults.

\section{Introducció}

\subsection{Concepte de teoria de la ment (TM)}

Tal com assenyala Adolphs (2001), la cognició social és un procés complex en el qual hi ha mecanismes per a percebre, processar i avaluar els estímuls de manera que es permet una representació de l'entorn social. Dins d'aquesta es troba l'habilitat coneguda com teoria de la ment (TM). Tal com afirmen Tirapu-Ustárroz, Pérez-Sayes, Erekatxo- 
Bilbao i Pelegrín-Valero (2007), existeix una terminologia molt variada Iligada a aquest concepte: "ToM» (Theory of Mind), "cognició social», «mentalització», «psicologia popular», «psicologia intuïtiva» o «conducta intencional». Comunament, s'accepta de que es tracta de I'habilitat per a comprendre i predir la conducta d'altres persones, els seus coneixements, intencions i creences (Tirapu-Ustárroz et al., 2007). Segons aquests autors, la TM es compon d'un conjunt d'habilitats metacognitives complexes entre les quals es poden identificar components com el reconeixement facial d'emocions, la comprensió de creences de primer i segon ordre, la d'expressions metafòriques, el reconeixement de posades de pota (faux pas, en francés), l'expressió emocional a través de la mirada, o l'empatia i el judici moral.

Actualment, des de l'àmbit de la psicologia evolutiva, es concreta la TM com la capacitat per a reconèixer $i$ atribuir estats mentals a un mateix i als altres (Benson, Abbeduto, Short, Bibler i Maas, 1993; Giaouri, Alevriadou i Tsakiridou, 2010), poder-los reconèixer com a iguals o diferents (Yirmiya, Solomonica-Levi i Shulman, 1996), a part d'utilitzar-la per a comprendre i predir el propi comportament i el dels altres en tots els seus contextos socials en els quals es desenvolupen (Wellman, 1990). No es tracta d'una habilitat que s'ensenya explícitament als infants, sinó que s'aprén amb l'experiència (Premack i Woodruf, 1978). Per tant, tenir TM es un prerequisit per a la interacció humana, fonamental per a la supervivència en la societat (Yirmiya, Erel, Shaked i Solomonica-Levi, 1998).

\subsection{Nivells de complexitat i avaluació de TM}

En l'àmbit evolutiu, i com a fita clau de TM, es considera que sobre els 4-5 anys els xiquets i les xiquetes comencen a distingir clarament entre representacions mentals i realitat (fita que s'avalua amb la tasca clàssica de falses creences), el que els permet predir l'actuació d'una persona segons les seues creences (Perner, 1991; Wellman, 1990). I durant l'etapa escolar, es desenvolupen distintes habilitats de TM fins arribar a l'adolescència. En aquest sentit, segons la classificació de Tirapu-Ustárroz, et al. (2007) hi ha distints nivells de complexitat, tenint avui en dia un repertori ampli de distintes tasques per avaluar-los, més enllà de l'avaluació de la falsa creença. Aquests nivells són els següents:

- Reconeixement facial d'emocions: competència en reconèixer emocions mitjançant l'observació d'expressions facials.

- Falses creences de primer i segon ordre: ser capaç de posarse en la situació d'altra persona, ometent la informació adquirida, i així poder predir l'acció que realitzarà en determinat context. Segons la seua complexitat n'hi ha de primer i de segon ordre.

- «Posades de pota» (o malentesos): Baron-Cohen, O’Riordan, Stone, Jones i Plaisted (1999) defineixen la comprensió de 
"posades de pota» com quan algú diu alguna cosa sense tenir en compte (o saber) si l'oient ho vol escoltar, de manera que pot comportar conseqüències negatives per a aquest sense ser intencionades per part del parlant.

- Expressió i comprensió emocional a través de la mirada: es tracta d'un dels nivells de cognició social amb més dificultats, atés que inclouria la capacitat de reconèixer emocions i estats mentals complexos a través de la mirada (Baron-Cohen, Wheelwright, Scahill, Lawson i Spong, 2001).

- Empatia i judici moral: aquest nivell ha suscitat un gran debat i polèmica entre els que estudien la conducta humana, però es considera part de la TM ja que existeix un solapament entre les regions cerebrals implicades en aquesta $\mathrm{i}$ les implicades en els judicis ètics $\mathrm{i}$ "dilemes morals».

- Comunicacions metafòriques i històries estranyes: competència a l'hora de detectar intencions sota enunciats literals o metafòrics.

\subsection{Teories d'adquisició i poblacions amb dificultats}

L'origen de la TM, es troba en els primers treballs de Premack $i$ Woodruf (1978) quan van intentar demostrar que els ximpanzés podien comprendre la ment dels éssers humans. Són diverses les postures adoptades entorn a l'adquisició de les dificultats en TM.

Les primeres teories, com la proposada per Leslie (1987), suggerien que aquest mecanisme pot ser innat, específic i independent (ToMM o Theory of Mind Module), i per tant, una persona amb una intel-ligència típica en altres aspectes, el puga tenir afectat d'una manera independent com ocorreria en el trastorn de l'espectre autista (TEA). Tanmateix, els últims anys, un gran nombre d'investigacions ha demostrat l'existència d'una relació entre el desenvolupament de la TM i el desenvolupament del llenguatge (Astington i Baird, 2005), ja que sembla clar que l'adquisició del llenguatge afavoreix el desenvolupament de la TM (i viceversa). A més, el desenvolupament més gran en TM és entre els 3 i 5 anys, coincidint amb el període de desenvolupament i consolidació del llenguatge (Astington i Jenkins, 1999). En aquest, es van veure correlacions entre proves de creença falsa i diferents mesures lingüístiques (vocabulari o memòria d'oracions) en xiquets i xiquetes d'aquest interval d'edat. Posteriorment, Milligan, Astington i Dack (2007) realitzaren una metaanàlisis on demostraren per mitjà de distints estudis que hi ha una intensa relació entre TM i les habilitats lingüístiques.

En aquest sentit, diversos autors han intentat identificar quins aspectes del llenguatge estan primordialment relacionats amb la TM, de manera que se li dóna èmfasis a la semàntica, la sintaxi, la pragmàtica o 
inclús el llenguatge en general (Serrano, 2012). Encara així, no està tan clar quin aspecte propi del llenguatge és el més relacionat amb el desenvolupament de la TM.

El que està clar i és comunament acceptat és que el llenguatge és un prerequisit per a iniciar o tenir relacions interpersonals amb iguals $i$, per tant, la mancança d'aquest pot contribuir a l'aparició de desajustos conductuals o un retard en el desenvolupament de la cognició social (Jerome, Fujiki, Brinton i James, 2002). Estudis com el de Bishop (1997) o el de Miller (2001) permeten afirmar que el fracàs en tasques de TM (p. ex., de creença falsa) està relacionat amb les capacitats lingüístiques. A més, dades empíriques provinents de poblacions amb dificultats comunicatives (autisme i síndrome de Down) sustenten que les dificultats pragmàtiques poden obeir a dèficits en la capacitat de formar-se teories de la ment dels interlocutors (Olivar, Flores i de la Iglesia, 2004). Tanmateix, autors com Farrant, Fletcher i Maybery (2006) afirmen que la mancança en la comprensió de les tasques de creença falsa no pot explicar-se exclusivament a partir de les demandes lingüístiques i memorístiques pròpies de la tasca, ni tampoc per l'ús adequat de conceptes sobre estat mental en les respostes. Així, altres autors com Varley, Siegal i Want (2001) observen que l'afectació en aspectes gramaticals en pacients amb dany cerebral (on el llenguatge ja estava desenvolupat) no influeix en la TM.

Aquesta relació de la TM amb el llenguatge es pot observar en persones amb un desenvolupament normotípic, però és més evident en persones amb trastorns que tenen afectada la comunicació (Happé, 1995; Pons, Lawson, Harris i de Rosnay, 2003). De fet, en un principi, es va afirmar que les dificultats en TM eren específiques de les persones amb autisme (etiologia de la seua simptomatologia) i es va proposar que la causa dels trastorns generals del desenvolupament era una absència d'aquesta habilitat (Baron-Cohen, Leslie i Friht, 1985). El dèficit bàsic de les persones en autisme radica en la incompetència per a formar-se representacions mentals sobre creences, pensaments i intencions dels altres i diferenciar-les d'un mateix, la qual cosa suposa una incapacitat per a entendre els estats mentals o perspectives diferents als propis (Baron-Cohen, et al., 1985).

Les persones amb trastorn específic del llenguatge (TEL) són un altra de les poblacions amb dificultats per al desenvolupament de la TM, no tan greus com en l'autisme, però el retard en el desenvolupament del llenguatge provoca un desfasament de 2 a 3 anys en algunes habilitats bàsiques, com ara la comprensió de creences falses (Andrés-Roqueta, Adrian, Clemente i Katsos, 2013). "Llenguatge i TM estan entrellaçats durant les fases inicials del desenvolupament i interaccionen de manera dinàmica i constant» (Andrés, 2009: 23). Aquestes dificultats es tradueixen, per exemple, a l'hora d'interaccionar amb iguals demostrant habilitats de negociació pobres i resolució de conflictes improductius (Brinton, Fujiki i McKee, 1998) i tenint dificultat per a iniciar interaccions socials (Brinton, Fujiki, Spencer i Robinson, 1997). 
Un tercer col-lectiu amb retards en el desenvolupament de la TM és la població amb dèficit auditiu que naixen en famílies oients (coneguts com late-signers) ja que també presenten retards comunicatius a causa d'un període de no-exposició a converses amb els adults del voltant ( $p$. ex., Peterson i Siegal, 2000; Schick, de Villiers, de Villiers i Hoffmeister, 2007). A mesura que els xiquets amb sordesa aprenen el llenguatge de símbols van assolint la capacitat de comunicar-se i conseqüentment van desenvolupant les seues habilitats mentalistes (Peterson i Siegal, 1995).

Finalment, i en relació amb la població que s'estudia en aquest article, també s'han trobat dificultats de TM en persones amb discapacitat intel-lectual (DI), i més concretament, s'ha estudiat el cas de les persones amb síndrome de Down (SD). Tanmateix, la quantitat d'evidències empíriques és més baixa que en la resta de trastorns esmentats, sobretot en persones adultes, i una sèrie d'estereotips sobre aquestes persones ha comportat que avui en dia encara no es tinga clar quines habilitats de TM tenen aquestes persones, en comparació amb les persones de la seua edat.

\subsection{Síndrome de Down (SD) i teoria de la ment (TM)}

La SD és una alteració genètica pròpia de l'espècie humana des dels seus orígens (Amadó, 2014). Aquesta alteració ve donada per una trisomia en el cromosoma 21, és a dir, en compte de dos cromosomes en el parell 21, en tenen tres. Segons Lambert i Rondal (1982) formen el $25 \%$ de les persones amb discapacitat intel-lectual (DI). Pel que fa a les seues dificultats, s'ha demostrat que les habilitats lingüístiques i comunicatives en les persones amb SD no es desenvolupen seguint el mateix patró que la resta d'habilitats cognitives (Chapman, 1995; Miller, 1987), ja que, en general, el seu nivell lingüístic sol ser inferior al nivell de competència social i intel-lectual (Ruiz, 2001). A més a més, és important tenir present que entre les persones amb SD existeix una gran variabilitat entre uns individus i altres, encara que aquestes persones presenten un retard significatiu en l'emergència del llenguatge i les habilitats lingüístiques (Miller, Leddy i Leavitt, 2001).

La percepció estereotipada que les persones amb SD són «molt sociables», pot ser un dels factors que més contribueix a la falta d'estudis sobre aquest tema (Down, 1866; Fidler, Most, Booth-LaForce i Kelly, 2008; Gilmore, Campbell i Cuskelly, 2003; Hines i Bennett, 1996; Rogers, 1987; Wishart i Johnston, 1990; Wishart i Manning, 1996).

A més, la major part d'estudis s'han basat en xiquets i xiquetes, i no tant en adults, com a conseqüència de prendre als xiquets amb SD com a «participants control» de xiquets amb TEA (p. ex., Yirmiya, Solomonica-Levi i Shulman, 1996), la qual cosa ha fet que algunes de les dificultats no s'hagen estudiat en profunditat, entre altres la font principal d'aquesta investigació, la comprensió acurada de les intencions comunicatives de les persones. 
Aquest últim nivell serà la font principal d'aquest estudi. Happé (1994), la creadora de la tasca més emprada per a tal motiu (tasca d'Històries Estranyes), afirma que aquestes històries estan situades en un nivell de complexitat més alt dins de la TM, ja que aquestes se centren en la capacitat per a extraure un significat en funció d'un context social particular (i no general). Per tant, són necessàries també les anomenades habilitats de "coherència central o global» per tal de superar el significat literal en un context concret.

En la tasca de Happé (1994), s'avalua la capacitat de comprendre les intencions comunicatives següents: mentida, mentida piadosa, acudit, ficció, malentés, persuasió, aparença vs. realitat, metàfora, sarcasme, oblit, doble engany i emocions oposades.

\section{Objectius}

Els dos principals objectius d'aquest estudi són:

1. Oferir un perfil comprensiu de les intencions comunicatives en persones adultes amb SD i DI, de manera que es complete la informació prèvia sobre competència emocional i comprensió de creences falses, atenent a factors que puguen afectar aquest desenvolupament com el tipus de DI (SD vs. altres DI).

2. Esbrinar si el llenguatge i el raonament no verbal, són variables predictores d'un nivell més bo en intencions comunicatives dins de la població adulta amb DI.

A partir d'aquests objectius es formulen les hipòtesis següents:

- Hipòtesis 1: després de la revisió de la literatura que versa sobre les habilitats implicades en el desenvolupament de la TM, s'hipotetitza que les dificultats en les intencions comunicatives estaran tant les persones amb DI, com les persones amb SD, ja que els dos grups tenen problemes en el llenguatge. No s'estableix cap hipòtesi pel que fa a quina població tindrà més problemes.

- Hipòtesis 2: per altra banda, s'hipotetitza que el llenguatge serà una variable predictora en les intencions comunicatives en les persones amb DI, tal com ocorre també en altres poblacions

\section{Material i mètode}

\subsection{Participants}

En aquest estudi van participar 36 adults amb DI d'edats compreses entre 17 i 52 anys ( $M=28$ anys; DT $=107.36$ mesos). Tots els 
participants procedeixen de la Fundació Síndrome de Down de Castelló de la Plana, on divideixen la seua modalitat d'escolarització en tres tipus: formal (22,2 \%), no formal $(63,9 \%)$ i ocupacional $(13,9 \%)$.

La informació sobre els participants s'ofereix en la Taula 1. Aquest grup es va dividir en dos:

- Grup amb síndrome de Down (SD): es van seleccionar 18 adults diagnosticats amb SD.

- Grup amb altres tipus de DI (DI): una vegada seleccionat el grup amb SD, es van reclutar participants del centre amb altres tipus de DI amb una edat i gènere semblants, per tal de formar el grup de comparació.

Cal aclarir que, encara que ambdós grups tenen discapacitat intel-lectual, en aquest article es farà referència amb els acrònims «SD" per referir-se al grup amb síndrome de Down, i «DI» per a referir-se al grup d'adults amb altres tipus de discapacitat intel-lectual.

\subsection{Instruments}

Instruments sobre les capacitats individuals: raonament no verbal $i$ habilitats lingüistiques.

- Raonament no verbal: Matrius progressives - escala de color (Raven, Court i Raven, 1996).

Es tracta d'una prova per a avaluar el $\mathrm{Cl}$ no verbal mitjançant 36 ítems de dificultat creixent i consisteix a assenyalar, entre sis opcions possibles, la peça que li falta en un puzle per a completar-lo. Es pot aconseguir una puntuació màxima de 36 punts. Tal com recomana el manual, s'ha administrat l'escala a color, ja que aquesta és molt apropiada per a valorar tant a xiquets com a adults d'una dotació intel-lectual baixa com és el cas del present estudi. Com que es treballar amb adults, s'utilitza la puntuació directa sense transformar-la en percentils.

- Habilitats lingüístiques:

a) Mesura gramatical: test de comprensió d'estructures gramaticals (CEG) (Mendoza, Carballo, Muñoz i Fresneda, 2005).

EI CEG mesura la comprensió d'estructures gramaticals en xiquets entre 4 i 11 anys. El test conté 80 ítems que consisteixen a assenyalar el dibuix, entre quatre de diferents, a què correspon l'enunciat llegit. Per tant, la puntuació directa per la suma d'ítems pot anar de 0 a 80 punts. Es poden traure percentils a partir de les puntuacions directes segons l'edat, tanmateix, en tractar-se d'adults amb l'edat mental més baixa que la cronològica, s'utilitzen les puntuacions directes.

b) Mesura de vocabulari: Peabody (Dunn, Dunn i Arribas, 2006)

El test de vocabulari en imatges Peabody (PPVT-III) mesura el coeficient verbal de xiquets d'entre 2 i 17 anys. Consisteix a assenyalar 
el dibuix correcte, entre quatre opcions, que correspon a la paraula llegida. Els ítems d'aquesta prova s'organitzen per blocs de 12 ítems cada un per edats, i comencen de 2 anys i mig fins al de més grans de 17 anys. En el present estudi, com que es tracta de persones en edat adulta, no s'ha començat des del principi de la prova sinó del bloc de 6-7 anys. Si cometien una errada o més, es va anar baixant blocs fins arribat al primer. Mentre van encertant ítems, es va pujant blocs fins aplegar al «bloc sostre», és a dir, 8 errades o més en un mateix bloc. D’aquest test també s'ha utilitzat la puntuació directa com la resta de proves ja que no estan dissenyades per a adults. La puntuació total pot anar des dels 0 fins als 192 punts.

\section{Instrument sobre Intencions comunicatives}

- Històries Estranyes (Happé, 1994; adaptació Andrés, 2009).

Les Històries Estranyes avaluen aspectes de la vida quotidiana on ocorren episodis mentalistes, com ara la comprensió de la mentida, la mentida piadosa, la metàfora, els malentesos, el doble engany, la ironia, la persuasió, les emocions oposades, els zels, les intencions i les posades de pota. Aquestes històries es van crear inicialment per avaluar I'habilitat dels xiquets autistes a l'hora d'atribuir intencions als altres (Happé, 1994).

Per a aquest treball, s'han utilitzat un total de sis històries de les dotze originals: simulació, l'acudit, la mentida, la mentida piadosa, la ironia i la frase feta.

La forma d'administrar aquest test és contar cada història amb unes vinyetes utilitzades de suport visual. Per exemple, la història de "simulació» tracta sobre dues amigues, Maria i Rosa, que estan jugant a casa. De sobte Rosa agafa un plàtan del fruiter i se'l posa a l'orella i li diu a María que estava parlant per telèfon. En finalitzar la breu narració es formulen dues preguntes:

- Pregunta 1: És cert el que diu Rosa?

- Pregunta 2: Aleshores... Per què ho diu?

La puntuació de cada història oscil.la de 0 a 3 punts, en funció de l'apropament a la detecció de la intenció del protagonista (3 punts = intenció correcta; 2 punts = resposta correcta amb al.lusió a aspectes físics; 1 punt =intenció distinta; 0 punts $=$ respostes incoherents). Finalment se suma la puntuació total de les sis històries utilitzades fent servir aquesta com puntuació directa que pot anar des de 0 fins a 18 punts.

\subsection{Procediment}

En primer lloc es va contactar amb la Fundació Síndrome de Down de Castelló de la Plana per tal de poder realitzar allí el present estudi amb els seus alumnes. Posteriorment, es van sol-licitar tots els permisos 
pertinents en el centre per a realitzar la investigació i les autoritzacions per part dels alumnes i les seues famílies. Finalment, es van administrar les proves a la mostra escolaritzada en el centre de formació i del centre ocupacional.

Totes les proves van ser administrades en aules o despatxos que estaven lliures tant en el centre de formació com en l'ocupacional en l'horari escolar dels alumnes per part de l'autor de l'article i sempre de manera individual.

Finalment, les proves es van corregir i es van introduir en el paquet estadístic IBM SPSS Statistics 22 per a analitzar-les.

\section{Resultats}

A continuació es mostren els resultats obtinguts en les distintes mesures, atenent als objectius de l'estudi. En primer lloc, donades les característiques de la mostra, es van emprar proves no paramètriques ( $U$ de Mann-Whitney) per tal de comparar els grups SD i DI en les distintes mesures. Posteriorment, es va realitzar un estudi correlacional (Pearson) dins de cada grup per separat, així com en la globalitat de la mostra. I finalment, per tal d'esbrinar quins són els predictors d'un millor nivell de TM dins de la mostra amb DI, es va dur a terme un estudi predictiu amb distintes regressions lineals prenent les tasques de TM com a variables dependents.

\subsection{Descriptius i comparacions grupals de les variables lingüístiques i no verbals}

En la Taula 1 es pot veure la comparativa realitzada entre els dos grups que s'extrau de la mostra amb la prova $U$ de Mann-Whitney. Es tracta de grups equilibrats en edat, gènere i raonament no verbal.

En relació amb el llenguatge, s'observa una diferència significativa favorable al grup amb $D I$ en ambdues proves: gramàtica $(U=73,5$, $p=.004$, Cohen's $d=-.911)$ i vocabulari $(U=98,5, p=.044$, Cohen's $d=$ $.751)$.

Taula 1. Descriptius i comparacions grupals en les variables de control i selecció de la mostra

\begin{tabular}{|c|c|c|c|c|c|c|c|c|c|}
\hline & \multicolumn{3}{|c|}{$D I(n=18)$} & \multicolumn{3}{|c|}{$S D(n=18)$} & \multirow[b]{2}{*}{$d$} & \multirow[b]{2}{*}{$U$} & \multirow[b]{2}{*}{$p$} \\
\hline & $M$ & $D T$ & Rang & $M$ & $D T$ & Rang & & & \\
\hline Edat (mesos) & 357,17 & 132,83 & $215-627$ & 324,61 & 74,33 & $227-492$ & .302 & $\mathrm{DI}=\mathrm{SD}$ & $p=.791$ \\
\hline Gènere [M/F] & $11 / 7$ & - & - & $7 / 11$ & - & - & - & $\mathrm{DI}=\mathrm{SD}$ & $p=.265$ \\
\hline Cl no verbal & 18,33 & 10,36 & $2-34$ & 16,94 & 6,13 & $4-27$ & .163 & $\mathrm{DI}=\mathrm{SD}$ & $p=.767$ \\
\hline Gramàtica & 56,33 & 13,43 & $26-76$ & 45,11 & 11,09 & $30-73$ & .911 & $\mathrm{DI}>\mathrm{SD}$ & $p=.004$ \\
\hline Vocabulari & 109,67 & 38,14 & $40-179$ & 83,94 & 29,89 & $44-142$ & .751 & $\mathrm{DI}>\mathrm{SD}$ & $p=.044$ \\
\hline
\end{tabular}


Per tant, el grup de SD i el grup de DI es diferenciaren en el raonament no verbal, però fonamentalment en el seu nivell lingüístic, el grup amb DI va obtenir més bona puntuació en els dos casos.

\subsection{Descriptius $\mathbf{i}$ comparacions grupals en la tasca de les intencions comunicatives}

En el cas de les intencions comunicatives, s'han trobat diferències entre els dos grups experimentals, com es pot observar en la comparació de les puntuacions mitjanes que apareixen a la Taula 2.

$\mathrm{Hi}$ ha una diferència significativa en el total de les intencions comunicatives (Històries Estranyes) $(U=75, p=.005, d=1,068)$. En el desglossament d'aquesta tasca, es poden veure diferències significatives en la simulació $(U=72, p=.004, d=1,101)$ i en la mentida piadosa $(U=65, p=.002, d=1,403)$. També s'aprecia una diferència amb tendència a la significació en la ironia $(U=101,5, p=.055, d=.749)$. En tots els casos, el grup amb DI demostra una competència superior.

Taula 2. Descriptius i comparacions grupals en la tasca de les Històries Estranyes

\begin{tabular}{|c|c|c|c|c|c|c|c|c|c|}
\hline & \multicolumn{3}{|c|}{$D I(n=18)$} & \multicolumn{3}{|c|}{$S D(n=18)$} & \multirow[b]{2}{*}{$d$} & \multirow[b]{2}{*}{$\boldsymbol{U}$} & \multirow[b]{2}{*}{$p$} \\
\hline & $M$ & $D T$ & Rang & $M$ & $D T$ & Rang & & & \\
\hline H1. Simulació & 1,61 & 1,24 & $0-3$ & .44 & .85 & $0-3$ & 1,101 & $\mathrm{DI}>\mathrm{SD}$ & $p=.004$ \\
\hline H2. Acudit & 1,22 & 1,00 & $0-2$ & .89 & 1,02 & $0-2$ & .327 & $\mathrm{DI}=\mathrm{SD}$ & $p=.406$ \\
\hline H3. Mentida & 2,61 & .99 & $0-3$ & 2,00 & 1,33 & $0-3$ & .520 & $\mathrm{DI}=\mathrm{SD}$ & $p=.252$ \\
\hline H4. M. piadosa & 2,11 & 1,23 & $0-3$ & .67 & .77 & $0-3$ & 1,403 & $\mathrm{DI}>\mathrm{SD}$ & $p=.002$ \\
\hline H5. Ironia & 1,89 & 1,45 & $0-3$ & .83 & 1,38 & $0-3$ & .749 & $\mathrm{DI}>\mathrm{SD}$ & $p=.055$ \\
\hline H6. Frase feta & 1,28 & .96 & $0-3$ & 1,05 & 1,05 & $0-3$ & .229 & $\mathrm{DI}=\mathrm{SD}$ & $p=.481$ \\
\hline H. Estranyes (total) & 10,72 & 5,52 & $0-17$ & 5,89 & 3,23 & $0-11$ & 1,068 & $\mathrm{DI}>\mathrm{SD}$ & $p=.005$ \\
\hline
\end{tabular}

\subsection{Correlacions entre la tasca de les intencions comunicatives i la resta} de mesures

En aquest estudi s'han fet dos estudis correlacionals diferents: dins de la mostra de DI $(n=18)$ i dins de la mostra de SD $(n=18)$. S'ha emprat la correlació de Pearson i sempre entre les variables i la tasca de les Històries Estranyes (HE). Aquestes dues correlacions estan representades en la Taula 3.

\subsubsection{Correlacions del grup amb DI}

$S^{\prime}$ observen correlacions significatives dels aspectes relacionats amb el llenguatge (vocabulari i gramàtica) amb totes les HE inclús en el valor total. També s'aprecia una correlació amb tendència a la significació del raonament no verbal amb el valor total de les HE i amb l'acudit. 


\subsubsection{Correlacions del grup amb SD}

Ací s'observen menys correlacions significatives. En relació amb el llenguatge, es descobreix una correlació de la gramàtica amb el total de les $\mathrm{HE}$, amb la mentida i amb la ironia, en canvi, en el vocabulari soles s'aprecia una tendència a la significació amb el total de les HE.

Pel que fa al raonament no verbal, apareixen tan sols dues tendències a la significació, una a la mentida i altra a la ironia

Taula 3. Correlacions de la mostra

\begin{tabular}{lcccccc}
\hline & \multicolumn{3}{c}{$D I(n=18)$} & \multicolumn{3}{c}{ SD $(n=18)$} \\
\hline H1. Simulació & $.574^{*}$ & $.484^{*}$ & .289 & -.077 & -.241 & -.074 \\
\hline H2. Acudit & $.632^{* *}$ & $.762^{* *}$ & $.445(\mathrm{t})$ & .160 & .261 & .027 \\
\hline H3. Mentida & $.603^{* *}$ & $.677^{* *}$ & .176 & .292 & $.539^{*}$ & $.448(\mathrm{t})$ \\
\hline H4. M. piadosa & $.507^{*}$ & $.638^{* *}$ & .334 & .287 & .032 & -.092 \\
\hline H5. Ironia & $.673^{* *}$ & $.681^{* *}$ & .320 & .373 & $.500^{*}$ & $.443(\mathrm{t})$ \\
\hline H6. Frase feta & $.563^{*}$ & $.751^{* *}$ & .393 & .201 & .020 & .064 \\
\hline H. Estranyes (total) & $.739^{* *}$ & $.819^{* *}$ & $.404(\mathrm{t})$ & $.443(\mathrm{t})$ & $.468^{*}$ & .362 \\
\hline
\end{tabular}

Nota: ${ }^{*} p<.05 ;{ }^{* *} p<.01 ;(t)$ tendència $.05<.10$

\section{Discussió i conclusions}

Al principi d'aquest estudi es plantejaven dos objectius principals. El primer objectiu era oferir un perfil comprensiu de les intencions comunicatives en persones adultes amb SD i DI, i ampliar la informació prèvia sobre competència emocional i comprensió de creences falses, atenent a factors que puguen afectar aquest desenvolupament com el tipus de DI: per una part SD i per l'altra altres tipus de DI. En aquest sentit, s'hipotetitzava que les dificultats en comprensió d'intencions comunicatives estarien presents tant en les persones amb DI, com en les persones amb SD, ja que els dos grups tenen problemes amb el llenguatge i amb funcions executives. Pel que fa a quina població tindrà més problemes, no s'establia cap hipòtesi.

Després de la realització d'aquest estudi, es pot afirmar que s'ha confirmat que les persones adultes amb SD i altres tipus de DI tenen dificultats per a resoldre tasques d'intencions comunicatives que haurien de ser superades entre els 6 i els 11 anys, com ara quan les persones volen realitzar una broma, dir una mentida o parlar de manera irònica per a demostrar allò contrari. A més, i com a dada important trobada en aquest estudi, cal remarcar que els adults amb SD tenen, fins i tot, més problemes pera resoldre les tasques que altres adults amb altres tipus de DI. 
Així, s'ha demostrat que encara que les persones adultes amb SD no tinguen problemes per a superar tasques simples de TM (com ara, reconeixement d'emocions simples o creences falses), les seues dificultats afloren en aquest nivell de TM que amb anterioritat no havia sigut explorat. Aquestes dificultats podrien explicar que les persones amb SD tinguen de vegades biaixos a l'hora d'interpretar la conducta de les persones que els envolten i, per exemple, no captar subtileses com la «no-intencionalitat» de ferir en una mentida piadosa.

El segon objectiu plantejat en aquest estudi era esbrinar si el llenguatge i el raonament no verbal són variables predictores d'un nivell més bo en intencions comunicatives dins de la població adulta amb DI (en aquest cas, sense diferenciar entre SD i altres tipus de DI). A partir de les evidències prèvies de la literatura, s'hipotetitzava que dins del col-lectiu d'adults amb DI, les variables lingüístiques predirien més bé aquest nivell de TM, d'una manera semblant al que passa en altres poblacions (Andrés-Roqueta et al., 2013).

Seguint aquest objectiu i analitzant aquest treball, es pot afirmar que, tal com ocorre en la major part de poblacions amb i sense dificultats (per exemple, Astington i Baird, 2005; Bishop, 1997; Miller, 2001; Milligan, et al., 2007), la comprensió de totes les intencions comunicatives correlacionen significativament amb el llenguatge (mesurat en aquest estudi mitjançant dues tasques: comprensió gramatical i comprensió de vocabulari). Per tant, es pot confirmar que aquells individus amb més dèficit en el llenguatge dins del col·lectiu amb DI són els que han demostrat pitjor competència en la comprensió d'intencions comunicatives (i no aquells amb un $\mathrm{Cl}$ no verbal més baix).

Generalment, doncs, es pot afirmar que aquest nivell de TM està significativament relacionat amb el llenguatge, sobretot en el grup amb DI més que en el grup amb SD i guarden menys relació amb altres aspectes on també aquestes persones poden mostrar dificultats, com ara el raonament no verbal. Per tant, sembla que la tasca d'Històries Estranyes (Happé, 1994) requereix un bon nivell en vocabulari per poder comprendre-la i demostrar-ne una execució competent.

Com a conclusió general, es pot afirmar que les persones amb SD i DI sí que presenten certs problemes amb la comprensió de les intencions comunicatives i, per tant, en les seues habilitats de TM. En aquests termes no s'havia trobat informació al respecte, però altres autors com Fernández-Alcaraz, et al. (2010), ja afirmaven que les persones amb SD sí que tenen problemes en TM, sobretot en el reconeixement d'emocions. També s'han trobat estudis que afirmen que en alguns nivells de TM els adults continuen millorant a mesura que transcorre el seu desenvolupament (Giaouri, et al., 2010; Yirmiya, et al., 1998), per tant, caldria comprovar si en la comprensió de les intencions comunicatives passaria el mateix. Si així fóra, seria important dissenyar mètodes d'intervenció adaptats a les dificultats particulars de TM d'aquestes persones, de manera que se supere l'estereotip que no tenen dificultats a l'hora de relacionar-se amb les persones. El disseny 
d'aquest tipus d'intervencions és indispensable en aquesta població independentment del $\mathrm{Cl}$, sobretot en l'edat adulta, i habitualment no se li sol donar prou importància i, en canvi, resulta essencial per a establir correctament relacions interpersonals i una bona socialització amb el món que els envolta. A més, es podria millorar fins i tot l'autoestima i la qualitat de vida d'aquests col-lectius.

Com a dada rellevant d'aquest estudi es demostra l'existència de dificultats en TM que són importants a l'hora de relacionar-se amb les persones, com ara la comprensió d'intencions comunicatives amagades sota enunciats indirectes o no literals (frases fetes, mentides, ironies, etc.), entre d'altres.

En futurs estudis seria interessant administrar aquestes mateixes tasques a un grup control d'edat mental i lingüística similar al grup d'adults per a realitzar-ne la comparativa, de manera que es puguen estudiar amb profunditat els problemes concrets de la població amb SD i DI respecte a la població amb desenvolupament normotípic. Així mateix, també seria convenient estudiar altres variables que podrien estar implicades, tant en l'àmbit intrapersonal (p. ex. funcions executives), com en l'interpersonal (p. ex. estils paterns o socialització entre iguals).

\section{Agraïments}

Aquest estudi ha estat possible gràcies a la Fundació Síndrome de Down de Castelló de la Plana, tant al Centre de Formació com al Centre Ocupacional. Els autors volen agrair els directors, professionals i alumnes, per donar l'oportunitat de realitzar l'estudi. A més, els autors volen agrair a l'ajuda finançada atorgada pel projecte GV/2015/092 subvencionat per la Conselleria d'Educació, Cultura i Esport de la Generalitat Valenciana (Espanya).

\section{Bibliografia}

AdolPhs, R. (2001): "The Neurobiology of Social Cognition», Current Opinion in Neurobiology, 11, p. 231-9.

AMADó, A. (2014): Habilitats sociocognitives i de funcionament executiu en nenes i nens amb síndrome de Down d'entre 4 i 12 anys, Tesis Doctoral no publicada, Universitat de Girona, Girona.

ANDRÉs, C. (2009): Pragmática y cognición social en niños y niñas con trastorno específico del lenguaje (TEL), Tesis Doctoral no publicada, Universitat Jaume I, Castelló de la Plana.

Andrés-Roqueta, C. i altres (ed.) (2013): «Which are the Best Predictors of Theory of Mind Delay in Children with Specific Language Impairment?», International Journal of Language and Communication Disorders, 48 (6), p. 726-37. 
Astington, J. W. i J. BAIRD (2005): «Introduction: Why Language Matters», Why Language Matters for Theory of Mind, Oxford, Nova York, p. 3-25.

Astington, J. W. i J. M. Jenkins (1999): «A Longitudinal Study of the Relation Between Language and Theory-of-Mind Development», Developmental Psychology, 35, p. 1311-1320.

BARon-Cohen, S. i altres (ed.) (1985): «Does the Autistic Children Have a "Theory of Mind"?» Cognition, 21, p. 113-125.

- (1999): «Recognition of Faux Pas by Normally Developing Children and Children with Asperger Syndrome or High- Functioning Autism», Journal of Autism and Developmental Disorders, 29, p. 407-418. doi: 10.1023/A:1023035012436.

- (2001): "The 'Reading the Mind in the Eyes' Test Revised Version: A Study with Normal Adults, and Adults with Asperger Syndrome or HighFunctioning Autism», Journal of Child Psychology and Psychiatry, 42, p. 241-51.

Benson, G. i altres (ed.) (1993): "Development of Theory of Mind in Individuals with MR», American Journal on Mental Retardation, 98, p. 427-433.

BISHOP, D. V. M. (1997): Uncommon Understanding, Psychology Press, Hove, UK.

BRINTON, B. i altres (ed.) (1997): "The Ability of Children with Specific Language Impairment to Access and Participate in Ongoing Interaction", Journal of Speech, Language, and Hearing Research, 40 (5), p. 1011-1025.

BRINTON, B. i altres (ed.) (1998): «Negotiation Skills of Children with Specific Language Impairment», Journal of Speech, Language and Hearing Research, 41 (4), p. 927-940.

CHAPMAN, R. S. (1995): «Language Development in Children and Adolescents with Down Syndrome», FletCher, P. i B. MacWhinney (ed.), Handbook of Child Language, Blackwell, Oxford, p. 651-663.

Down, J. L. H. (1866): «Observations on an Ethnic Classification of Idiots», London Hospital Clinical Lectures and Reports, 3, p. 259-62.

DUNN, LL. M. i altres (ed.) (2006): Test de vocabulario en imágenes Peabody (PPVT-III), TEA Ediciones, Madrid.

FARRANT, B. i altres (ed.) (2006): "Specific Language Impairment, Theory of Mind, and Visual Perspective Taking: Evidence for Simulation Theory and the Developmental Role of Language», Child Development, 77, p. 18421853. doi:10.1111/j.1467- 8624.2006.00977.x

Fernández-Alcaraz, C. i altres (ed.) (2010): «Emotion Recognition in Down's Syndrome Adults: Neuropsychology Approach», Procedia Social and Behavioral Sciences, 5, p. 2072-2076, Universidad Autónoma de Madrid, Madrid. 
FIDLER, D. J. i altres (ed.) (2008): «Emerging Social Strengths in Young Children with Down Syndrome», Infants and Young Children, 21, p. 20720.

GIAOURI, S. i altres (ed.) (2010): «Theory of Mind Abilities in Children with Down Syndrome and Non-Specific Intellectual Disabilities: An Empirical Study with Some Educational Implications», Procedia Social and Behavioral Sciences, 2, p. 3883-3887.

GILMORE, L. i altres (ed.) (2003): «Developmental Expectations, Personality Stereotypes and Attitudes Towards Inclusive Education: Community and Teacher Views of Down Syndrome», International Journal of Disability Development and Education, 50, p. 63-78.

HAPPÉ, F. (1994): «An Advanced Test of Theory of Mind: Understanding of Story Characters' Thoughts and Feelings by Able Autistic, Mentally Handicapped, and Normal Children and Adults", Journal of Autism and Developmental Disorders, 24, p. 129-154. doi:10.1007/BF02172093.

- (1995): "The Role of Age and Verbal Ability in the Theory of Mind Task Performance of Subjects With Autism», Child Development, 66, p. 843855.

HINES S. i F. BENNETT (1996): «Effectiveness of Early Intervention for Children With Down Syndrome», Ment Retard Development Disabilities Research Reviews, 2, p. 96-101.

Jerome, A. C. i altres (ed.) (2002): "Self-Esteem in Children With Specific Language Impairment», Journal of Speech, Language, and Hearing Research, 45, p. 700-714.

LAMBERT, J. L. i J. A. RONDAL (1982): El mongolismo, Herder, Barcelona.

LESLIE, A. M. (1987): «Presence and Representation: The Origins of 'Theory of Mind'», Psychology Review, 94, p. 412-36.

MendozA, E. i altres (ed.) (2005): Test de comprensión de estructuras gramaticales, TEA ediciones, Madrid.

Miller, C. A. (2001): «False Belief Understanding in Children With Specific Language Impairment», Journal of Communication Disorders, 34, p. 73-86. doi:10.1016/S0021-9924(00)00042-3.

MilLeR, J. F. (1987): "Language and Communication Characteristics of Children with Down Syndrome», S. Pueschel, C. TIngey, J. Rynders, A. Crocker i D. Crutcher (ed.), New Perspectives on Down Syndrome (p. 233262), Paul Brookes, Baltimore, MD.

Miller, J. F. i altres (ed.) (2001): Síndrome de Down: comunicación, lenguaje y habla, Masson, Barcelona.

MilligAN, K. i altres (ed.) (2007): "Language and Theory of Mind: MetaAnalysis of the Relation Between Language Ability and False Belief Understanding", Child Development, 78 (2), p. 622-646. doi:10.1111/j.1467-8624.2007.01018.x. 
OLIVAR, J. S. i altres (ed.) (2004): «Relación entre teoría de la mente y comunicación referencial. Una explicación de los déficits pragmáticos en personas con autismo y síndrome de Down», Acción Psicológica, 3 (1), p. 31-42.

PERNER, J. (1991): Understanding the Representational Mind, MA: MIT Press, Cambridge.

Peterson, C. C. i M. Siegal (1995): «Deafness, Conversation and Theory of Mind», Journal of Child Psychology and Psychiatry, 36, p. 459-474. doi: 10.1111/j.14697610.1995.tb01303.x.

- (2000): "Insights into a Theory of Mind from Deafness and Autism», Mind and Language, 15, p. 77-99.

Pons, F. i altres (ed.) (2003): «Individual Differences in Children's Emotion Understanding: Effects of Age and Language», Scandinavian Journal of Psychology, 44, p. 347-353.

Premack D. i G. WoOdruff (1978): «Does Chimpanzee Have a Theory of Mind?", Behavioral and Brain Sciences, 4, 9-30.

RAVEN, J. C. i altres (ed.) (1996): Raven. Matrices progresivas. Escalas Color (CPM), General (SPM), Superior (APM), TEA Ediciones, Madrid.

ROGERS C. (1987): "Maternal Support for the Down's Syndrome Stereotype: The Effect of Direct Experience of the Condition", Journal of Mental Deficiency Research, 31, p. 271-8.

RUIZ, E. (2001): «Evaluación de la capacidad intelectual en personas con síndrome de Down», Revista de Síndrome de Down, 18, p. 80-88.

SCHICK, B. i altres (ed.) (2007): «Language and Theory of Mind: A Study of Deaf Children», Child Development, 78, p. 376-396.

SERRANO, J. (2012): Desarrollo de la teoría de la mente, lenguaje y funciones ejecutivas en niños de 4 a 12 años, Tesis Doctoral no publicada, Universitat de Girona, Girona.

TIRAPU-USTÁRROZ, J. i altres (ed.) (2007): «¿Qué es la teoría de la mente?», Revista de Neurología, 44 (8), p. 479-489.

Wellman, H. M. (1990): The Child's Theory of Mind, MA: MIT Press, Cambridge.

WISHART, J. G. i F. H. JOHNSTON (1990): «The Effects of Experience on Attribution of A Stereotyped Personality To Children With Down's Syndrome», Journal of Mental Deficiency Research, 34, p. 409-20.

WISHART, J. G. i G. MANNING (1996): "Trainee Teachers' Attitudes To Inclusive Education for Children With Down's Syndrome», Journal of Intellectual Disability Research, 40, p. 56-65.

YIRMIYA, N. i altres (ed.) (1996): "The Ability To Manipulate Behavior and To Understand Manipulation of Beliefs: A Comparison of Individuals With 
Autism, Mental Retardation, and Normal Development», Developmental Psychology, 32, p. 62-69.

- (1998): «Meta-Analyses Comparing Theory of Mind Abilities in Individuals with Autism, Individuals with Mental Retardation, and Normally Developing Individuals», Psychological Bulletin, 124, p. 283-305.

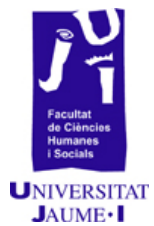

